POLYMER SCIENCE AND TECHNOLOGY Volume 21

\title{
Modification of Polymers
}




\section{POLYMER SCIENCE AND TECHNOLOGY}

\section{Editorial Board:}

William J. Bailey, University of Maryland, College Park, Maryland J. P. Berry, Rubber and Plastics Research Association of Great Britain, Shawbury, Shrewsbury, England

A. T. DiBenedetto, The University of Connecticut, Storrs, Connecticut

C. A. J. Hoeve, Texas A \& M University, College Station, Texas

Yōlchi Ishida, Osaka University, Toyonaka, Osaka, Japan

Frank E. Karasz, University of Massachusetts, Amherst, Massachusetts

Oslas Solomon, Franklin Institute, Philadelphia, Pennsylvania

Recent volumes in the series:

Volume 11 POLYMER ALLOYS II: Blends, Blocks, Grafts, and Interpenetrating Networks Edited by Daniel Klempner and Kurt C. Frisch

Volume 12 ADHESION AND ADSORPTION OF POLYMERS (Parts A and B) Edited by Lieng-Huang Lee

Volume 13 ULTRAFILTRATION MEMBRANES AND APPLICATIONS Edited by Anthony R. Cooper

Volume 14 BIOMEDICAL AND DENTAL APPLICATIONS OF POLYMERS Edited by Charles $G$. Gebelein and Frank F. Koblitz

Volume 15 CONDUCTIVE POLYMERS Edited by Raymond B. Seymour

Volume 16 POLYMERIC SEPARATION MEDIA Edited by Anthony R. Cooper

Volume 17 POLYMER APPLICATIONS OF RENEWABLE-RESOURCE MATERIALS Edited by Charles E. Carraher, Jr., and L. H. Sperling

Volume 18 REACTIONS INJECTION MOLDING AND FAST POLYMERIZATION REACTIONS Edited by Jiri E. Kresta

Volume 19 COORDINATION POLYMERIZATION

Edited by Charles C. Price and Edwin J. Vandenberg

Volume 20 POLYMER ALLOYS III: Blends, Blocks, Grafts, and Interpenetrating Networks Edited by Daniel Klempner and Kurt C. Frisch

Volume 21 MODIFICATION OF POLYMERS

Edited by Charles E. Carraher, Jr., and James A. Moore

A Continuation Order Plan is available for this series. A continuation order will bring delivery of each new volume immediately upon publication. Volumes are billed only upon actual shipment. For further information please contact the publisher. 


\title{
POLYMER SCIENCE AND TECHNOLOGY Volume 21
}

\section{Modification of Polymers}

\author{
Edited by \\ Charles E. Carraher, Jr.
}

Wright State University

Dayton, Ohio

$$
\text { and }
$$

James A. Moore

Rensselaer Polytechnic Institute

Troy, New York

Plenum Press - New York and London 
Library of Congress Cataloging in Publication Data

Symposium on Modification of Polymers (1982: Las Vegas, NV).

Modification of polymers.

(Polymer science and technology; v. 21)

"Proceedings of a symposium on modifiation of polymers, held March 29-31, 1982, at the ACS Meeting, in Las Vegas, Nevada"-Verso t.p.

Includes bibliographical references and index.

1. Polymers and polymerization-Congresses. I. Carraher, Charles E. II. Moore, J. A. (James Alfred). 1939-

QD380.M6 1983

668.9

ISBN-13:978-1-4613-3750-8

e-ISBN-13:978-1-4613-3748-5

83-11072

DOI: $10.1007 / 978-1-4613-3748-5$

Proceedings of a symposium on Modification of Polymers, held March 29-31, 1982, at the ACS Meeting, in Las Vegas, Nevada

(C) 1983 Plenum Press, New York

Softcover reprint of the hardcover 1st edition 1983

A Division of Plenum Publishing Corporation

233 Spring Street, New York, N.Y. 10013

All rights reserved

No part of this book may be reproduced, stored in a retrieval system, or transmitted in any form or by any means, electronic, mechanical, photocopying, microfilming, recording, or otherwise, without written permission from the Publisher 


\section{PREFACE}

The sheer volume of topics which could have been included under our general title prompted us to make some rather arbitrary decisions about content. Modification by irradiation is not included because the activity in this area is being treated elsewhere. We have chosen to emphasize chemical routes to modification and have striven to present as balanced a representation of current activity as time and page count permit. Industrial applications, both real and potential, are included. Where appropriate, we have encouraged the contributors to include review material to help provide the reader with adequate context.

The initial chapter is a review from a historical perspective of polymer modification and contains an extensive bibliography. The remainder of the book is divided into four general areas:

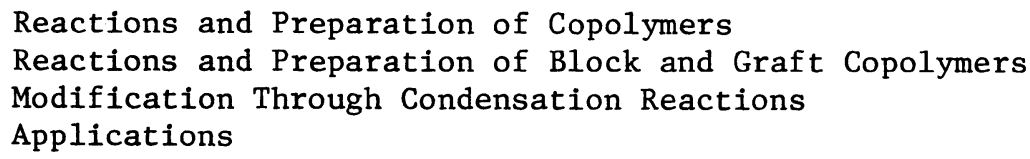

The chemical modification of homopolymers such as polyvinylchloride, polyethylene, poly(chloroalkylene sulfides), polysulfones, polychloromethylstyrene, polyisobutylene, polysodium acrylate, polyvinyl alcohol, polyviny1 chloroformate, sulfonated polystyrene; block and graft copolymers such as poly(styrene-block-ethylene-co-butyleneblock-styrene), poly(1,4-polybutadiene-block ethylene oxide), star chlorine-telechelic polyisobutylene, poly(isobutylene-co-2,3-dimethy11,3-butadiene), poly(styrene-co-N-butylmethacrylate); cellulose, dextran and inulin, is described.

A number of divergent applications are described here: modification of polymer surfaces (coatings, fibers, films and plastics); modifications leading to superior coating materials; isolation, concentration and containment of uranium; natural materials for insulation; synthesis of sugar substitutes; synthesis of anti-arrhythmic drugs; fibers which can be spun from chlorinated solvents yet dry cleaned; and synthesis of calcium ion selective electrode materials. 
Polymer modification is a broad, rapid1y expanding area of science and the enclosed chapters give glimpses of many of the more important areas. The contributors include a mix of eminent industrially and academically based scientists from any countries which give the book an international flavor.

We thank the authors for their valued contributions and Divisions of Organic Coatings and Plastics and Polymer Chemistry for their support. The cooperation of referees is also gratefully acknowledged.

Wright State University

Charles E. Carraher, Jr. Dayton, Ohio 45435

Rensselaer Polytechnic Institute

J. A. Moore

Troy, New York 12181 
CONTENTS

REVIEW

Modification of Polymers .................. 1

J. A. Moore and C. E. Carraher, Jr.

REACTIONS AND PREPARATIONS OF COPOLYMERS

Polymer Modification via Repeating Unit Isomerization. . . . 13

D. A. Tirrell, M. P. Zussman, J. S. Shih and

J. F. Brandt

Chemical Modification of Poly(styrenesulfone). . . . . . . 25

C. G. Willson, J. M. Fréchet and M. J. Farrall

The Effect of Additives for Accelerating Radiation Grafting:

The Use of the Technique for Modification of Polymers

Especially Polyolefins . . . . . . . . . . . . 33

C. H. Ang, J. L. Garnett, R. G. Levot and M. A. Long

The Halogenation of Poly [isobutylene-co-(2, 3-dimethyl-1, 3butadiene) ]. . . . . . . . . . . . . 53

I. Kuntz and B. E. Hudson, Jr.

Preparation and Properties of 2-Hydroxypropyl Methacrylate-

Alkyl Acrylate Copolymer Net-works . . . . . . . 65

G. N. Babu, A. Deshpande, P. K. Dhal and

D. D. Deshpande

Poly(enol-ketone) from the Oxidation of Poly(vinyl alcohol). .

S. J. Huang, I. F. Wang, and E. Quinga

Synthesis and Reaction of Poly(1,3-octadieny1 Iron Tri-

carbonyl). . . . . . . . . . . . . 85

T. W. Smith and D. J. Luca 
REACTIONS AND PREPARATION OF BLOCK AND GRAFT COPOLYMERS

Single and Compound Crosslinking of Polymer Systems. . . .

L. H. Sperling and D. E. Zurawski

Grafting on Polyvinylchloride in Suspension Using Phase

Transfer Catalysts or Solvents . . . . . . . . 109

A. Nkansah and G. Levin

Control of Polymer Surface Structure by Tailored Graft

Copolymers ................... 131

Y. Yamashita and Y. Tsukahara

Preparations of Block Copolymers by Chemical Reactions on Leamellas of Partially Crystalline Flexible Polymers ........................

A. E. Woodward

Graft Copolymerization of Maleic Anhydride onto Polyethylene

N. G. Gaylord, M. Mehta and V. Kumar

Masterbatched Polyethylene-Clay Composites Prepared

Through In Situ Graft Copolymerization of

Maleic Anhydride . . . . . . . . . . . . .

N. G. Gaylord and A. Takahashi

\section{MODIFICATION THROUGH CONDENSATION REACTIONS}

Reaction Variables in the Aqueous Solution Coordination of the Uranyl Ion with Polyacrylic Acid and Polysodium Acrylate. . . . . . . . . . . . . . . .

C. E. Carraher, Jr., S. Tsuji, W. A. Feld and J. E. Dinunzio

Coordination of the Uranyl Ion Through Reaction with Aqueous Solutions Containing Polyacrylic Acid and Polysodium Acrylate-Structural Considerations . . . . . . . .

C. E. Carraher, Jr., S. Tsuji, W. A. Feld and J. E. DiNunzio

Homogenous Chemical Modification of Cellulose: Further Studies on the DMSO-PF Solvent System. . . . . . . .

J. F. Kinstle and N. M. Irving

Chemical Modification of Polysaccharides - Modification of Dextran Through Interfacial Condensation with Organostannane Halides ...............

C. E. Carraher, Jr. and T. J. Gehrke 
Stable Polymer Eerified Sugar. . . . . . . . . . . 247

A. M. Usmani and I. O. Salyer

A New Polyblend: Polyesterimide Phenol-Formaldehyde Resin. . . . . . . . . . . . . . 257

S. Maitin and S. Das

Chemical Modification of Poly(vinyl Chloroformate) . . . . 293

G. Meunier, S. Boivin, P. Hémery, J-P. Senet and S. Boileau

Modified Polysaccharides with Potential Anti-Arrhythmic Activity . . . . . . . . . . . . . . 305

E. Schacht, L. Ruys, J. Vermeersch and E. Goethals

Variation on the Properties of Aromatic Polyesters by Changes in Isomer Distribution and Ring Substitution . 321

R. W. Stackman and A. G. Williams

Calcium Ion-Selective Electrodes with Covalently-Bound

Organophosphate Sensor Groups. . . . . . . . . . . 341

G. C. Corfield, L. Ebdon and A. T. Ellis

Dyed Sulfonated Polystyrene Films: Relationship of Triboelectric Charging and Molecular Orbital Energy Levels. . . . . . . . . . . . 353

H. W. Gibson

Organotin Polyimides: Structure-Property Relationships . . 373 G. N. Babu, C. P. Pathak and S. Samant

The Microstructure of Cyclized Polyisoprene. . . . . . . 383

D. B. Patterson, D. H. Beebe and J. La1

Contributors . . . . . . . . . . . . . . : 411

Index. . . . . . . . . . . . . . . 415 